\title{
Süperpiksel Küme Bölgeleri Tabanlı Aktif Çevrit Ve GrabCut Sinerjisini Kullanarak İnsan Kulağının Otomatik Bölütlenmesi*
}

\author{
Automatic Segmentation of the Human Ear Using Active Contour \\ and GrabCut Synergy Based on the Superpixel Cluster Regions
}

\author{
Bahadır Karasulu ${ }^{1}$ (D)
}

${ }^{*}$ Bu çalışma 8th International Conference on Future Learning and Informatics: Data Revolution (FL 2020) konferansında sözlü olarak sunulmuştur.

${ }^{1}$ (Doç. Dr.), Çanakkale Onsekiz Mart Üniversitesi, Mühendislik Fakültesi, Bilgisayar Mühendisliği Bölümü, Çanakkale, Türkiye

ORCID: B.K. 0000-0001-8524-874X

\section{Corresponding author:}

Bahadır KARASULU

Çanakkale Onsekiz Mart Üniversitesi,

Mühendislik Fakültesi, Bilgisayar Mühendisliği

Bölümü, Canakkale, Türkiye

E-mail address: bahadirkarasulu@.comu.edu.tr

Submitted: 20.01 .2021

Revision Requested: 03.03.2021

Last Revision Received: 16.03 .202

Accepted: 01.04.2021

Published Online: 12.05 .2021

Citation: Karasulu, B. (2021). Süperpiksel küme bölgeleri tabanlı aktif çevrit ve grabcut sinerjisini kullanarak insan kulağının otomatik bölütlenmesi. Acta Infologica, 5(1), 117-128.

https://doi.org/10.26650/acin.865375 öz

Kulak bölgesi bireyin yaşına bağlı olarak fizyolojik bakımdan çok az değişikliğe maruz kalan değerli biyometrik bilgi içeren bir insan vücut bölgesidir. Biyometrik bilgi elde etmede kulak bölgesinin kullanımıyla ilgili çeşitli yöntemlerde kulak bölgesinin elle, yarı otomatik veya tam otomatik olarak bölütlenmesi önemli bir araştırma alanıdır. Çalışmamızda, insan kulak bölgesinin görüntüden tam otomatik olarak bölütlenerek arka plandan ayrıştırılması için süperpiksel küme bölgeleri, jeodezik bilgiye dayanan aktif çevrit tespiti ve çizge kesme yoluyla ön plan ayrıştırma işlemleri uygulayan bir yaklaşım sunulmaktadır. Çalışmamızdaki bu yaklaşım sayesinde kulak ön plan maskesi programatik ve tam otomatik biçimde kulak görüntüsünden oluşturulmaktadır. Kulak görüntüleri veri kümesi ile yapılan deneylerde uzman tarafından işaretlenen referans kulak bölgesi maskesi otomatik olarak oluşturulan ön plan maskesi ile karşılaştırılmıştır. Jaccard endeksi ölçütüne dayalı benzerlik oranları (birleşim kesişimi) dikkate alındığında yüksek başarım değerleri elde edilmiştir. Yaklaşımımız bu veri kümesindeki görüntüler için \%84 ilâ \%92 aralığında oldukça iyi başarım değerlerine sahiptir. Çalışmamızda, önerilen sinerjik yaklaşımın başarımı hem niteliksel hem de niceliksel olarak deneysel sonuçlarla ortaya konulmaktadır..

Anahtar kelimeler: Süperpiksel, Aktif çevrit, Çizge kesme, Görüntü bölütleme

\section{ABSTRACT}

The ear region is a region of the human body region containing valuable biometric information that is subjected to a few physiological changes depending on the individual's age. Manual, semi-automatic, or fully automatic segmentation of the ear region in various methods related to the use of the ear region in obtaining biometric information is an important area of research. In our study, we present an approach that applies superpixel cluster regions, active contour detection based on geodesic information, and foreground separation by graph cutting, to segregate the human ear region from the image by fully automatic segmentation from the background. Thanks to this approach in our study, the ear foreground mask is created programmatically and fully automatically from the ear image. In the experiments with the ear images data set, the reference ear mask marked by the expert was compared with the automatically created foreground mask. It has been obtained hHigh performance values were obtained, considering the similarity rates (i.e., intersection over union) based on the Jaccard index metric. Our approach has quite good performance values (in the range of $84 \%$ to $92 \%$ ) for the images in this dataset. In our study, the success of the proposed synergistic approach is demonstrated both qualitatively and quantitatively with experimental results.

Keywords: Superpixel, Active contour, Graph cut, Image segmentation 


\section{GíRİ̧̧}

E-Sağlık ve turizm alanlarında bireylerin doğru olarak tanınabilmesi, kimlik tanımlama (identification), yetkilendirme (authentication) ve yetki geçerleme (validation) konularında birçok çalışma mevcuttur. Bu alandaki çalışmalar özellikle bireylerin günlük yaşantılarını aksatmamayı amaçlamaktadır. Temassız olarak bireyin kim olduğunun tespit edilmesi ve bireyin belirli süre zarfında temassız olarak takip edilmesine dayanan sistemlere olan ihtiyaç gün geçtikçe artmaktadır. Biyometrik; genel olarak ölçülebilen, fiziksel karakteristiğe sahip pratik uygulamaya yönelik, ayrıştırıcı, evrensel, kalıcıllı̆g olan ölçüm ve ölçütleri içermektedir. Bu bakış açısıyla tanımlama ve yetkilendirme sistemlerinde; ses kayıtları, parmak izleri, imzalar, el avuç içi geometrisi, göz iris, yüz görüntüleri, klavye tuş bilgileri gibi bilgiler biyometrik alanında üzerinde çalışılan uygun veriler olarak kullanılmaktadır (Tomczyk ve Szczepaniak, 2019). Biyometrik yetkilendirme sistemleri, bireylerin fizyolojik ve davranışsal ölçümlerini alarak bunları bireyin tanımlayıcı (kimlik) bilgisini onaylamada kullanmaktadır. Bu bilgilere dayanan karar verme, çıkarsama ve akıl yürütme işlemleri ile etiketleme (tagging), sınıflandırma (classification) ve tanıma (recognition) sonuçlarına yapılan deneylerle ulaşılmaktadır (Schuckers, 2010). Bu bilimsel bir yoldan günlük hayattaki güvenliğin (sağlık, turizm, askeri, finansal, eğitim ve benzeri) ölçülebilir, tekrar edilebilir ve sürdürülebilir bir hale gelmesi anlamina gelmektedir.

Bilgi modeli oluşturulurken kaynak, bu kaynaktan elde edilen özellikler ve bunların değerleri göz önüne alınmaktadır. Özellikle yüz görüntüleri son y1llarda derin öğrenme ve makine öğrenmesi tekniklerindeki gelişmelerle birlikte oldukça önem kazanmıştır. Fakat yüz bölgesinde yaşa bağlı oluşan değişimler, sakal, gözlük, şapka (gölge düşüren başlıklar) ve benzeri tespit ve tanımayı güçleştirici, örtücü olan veya diğer bireylerden ayrıştırıc1lı̆̆ı bozan öğeler bulunduğu durumlarda biyometrik bilginin elde edilme kalitesi düşmekte veya imkânsız hale gelebilmektedir. Bu açıdan yaş ile değişimle de olsa fizyolojik yapısındaki oranların görece sabit kaldığı bilinen ve başka nesnelerle daha az örtüşmeye maruz kalan fizyolojik bir vücut bölgesinin işlenmesi biyometrik açıdan önem kazanmıştır.

İnsan kulağ 1 içeren görüntülerin elde edilmesi diğer fizyolojik bölgelere göre nispeten daha kolaydır. İnsan kulağının anatomik bazı özellikleri yaşa bağlı olarak değişim gösterse de ayrıştırıcı olan iç ve dış kıvrımlarının geometrik oranları büyük çapta sabit kalmakta, yüz ifadesindeki değişimden etkilenmemektedir. Ayrıca, kulak geometrisinden kulağı ifade eden kenarların (edge) elde edilmesine dayalı yöntemler ile güçlü bir tanımlamanın yapılabilmesi mümkün olurken, kulağı kısmen örten saç, küpe, takı ve kulaklıkların görüntüden temizlenmesi de söz konusu olmaktadır. Özellikle, bu kulak kıvrımlarının belirleyici köşe noktalarına bazı görsel işaret noktalarının (landmark) yerleştirilmesi yoluyla (Cintas, Delriux, Navarro, Quinto-Sànchez, Pazas ve Gonzalez-Josè, 2019), iki boyutlu (2D) veya üç boyutlu (3D) kulak görüntülerinde değişik ışıklandırma, kamera bakış açısı ve bireyin kafasının konumu gibi çeşitli durumlar bilgi modelinin oluşturulmasında olumlu ya da olumsuz etki edebilmektedir. Bu işaret noktaları elle (manuel) veya otomatik olarak kulak üzerine yerleştirilmekte, bu sayede kulak bölütleme (ear segmentation) ve kulak tespiti (ear detection) gerçekleştirilebilmektedir. Ayrıca, kulak üzerine kulağı kapsayan çevrit (contour) yerleştirilmesi yoluyla kenar tabanlı bölütleme (edge-based segmentation) yapılabilmektedir. Özellikle literatürdeki çalışmalarda insan cilt rengi tespiti yoluyla ve kenar eğim şiddetinin (magnitude) artırılması yoluyla (Chen ve Bhanu, 2005) çevrit eşleme yapılabilmekte, bu sayede kulak tanıma (ear recognition) sonucu elde edilebilmektedir. Joshi ve Chauhan (2011) çalışmasında kulak tespiti için iki farklı yaklaşım önerilmiştir. Buna göre; ilk yaklaşım kenar tespitine dayanmakta, ikinci yaklaşımda ise şablon eşleme (template matching) ile kulak tespiti yapılmaktadır. Yapılan tespitlerin doğruluğu destek vektör makineleri (support vector machine) araciyla kontrol edilmiştir. Şablon eşlemede ise öklid mesafesi kullanılmıştır. Literatüre daha geniş açıdan bakan Emeršič ve ark. (2017) çalışmasında ve Pflug ve Busch (2012) çalışmasında da belirtildiği üzere; kulağın biçimine dayanan geometrik teknikler, kulağın genelini ele alarak kulak temsiline (representation) dayanan bütüncül (holistic) teknikler, yerel özniteliklerin elde edilmesiyle kulak ilgi noktalarının (point of interest) belirlenmesine dayanan yerel teknikler ve melez yaklaşımlar mevcuttur. Özellikle bütüncül tekniklerle kulak biçimini ortaya koymada kenar tespiti, çeşitli filtreler ve kuvvet alanı dönüşümlerinin de kullandığı görülmektedir. Bu sayede kulak tespiti ve kulak tanıma yüksek doğrulukta yapılabilmektedir. Khattab ve ark. (2014) çalışmasında, renkli görüntülerin bölütlenmesinde farklı renk uzayı modelleri için çizge kesme (graph cut) tekniği ile otomatik yoldan görüntüden nesnelerin bölütlenebilmesi üzerine çalışılmıştır. Bu sayede çeşitli doğal görüntüler üzerinden kıyaslama yapılarak çizge 
kesmenin otomatik görüntü bölütleme için başarımının oldukça yüksek olduğu kanıtlanmıştır. Bu yaklaşımın renkli kulak görüntülerinde kullanılabilmesi fikrine dayanarak çalışmamızda görüntüden nesne (kulak bölgesi) bölütlemeye dair bir sinerjik yaklaşım oluşturularak literatüre katkı olarak sunulmaktadır. Buna göre renk uzayı modelleri aracılığıyla görüntüdeki çeşitli küme bölgelerinin geometrik yapısı belirlenerek bütüncül bir teknikle aktif çevritin uygulanabildiği ve çizge kesmeye dayanarak oluşturulan bu sinerji sayesinde otomatik olarak kulak bölgesinin bölütlenmesi gerçekleştirilebilmektedir.

Çalışmamızda makine öğrenmesi kapsamında basit doğrusal iteratif kümeleme (simple linear iterative clustering, SLIC) yöntemi yoluyla süperpikseller ile oluşturulan kümelerin ifade ettiği bölgeler kullanılmaktadır. Bu yolla insan kulağının verilen görüntü içerisinde bulunduğu konumunun en uygun dış çevritini tespit edecek morfolojik jeodezik aktif çevrit (geodesic active contour, GAC) yöntemi uygulanabilmiştir. Bu sayede bu çevrit ile oluşturulan maske görüntüsüne bağlı olarak çizge tabanlı (GrabCut) biçimdeki iki seviyeli bölütleme (bi-level segmentation) yapılmaktadır. Bu bölütleme otomatik olarak jeodezik terim kullanan aktif çevrit ile bulunan kulak diş ve iç bölgesine dair bilgiyle oluşturulan maskenin GrabCut yönteminde kullanılarak çizge kesme yaklaşımıyla arka plan (background) ve ön plan (foreground) olarak görüntüden kulak nesnesinin otomatik bölütlemesi şeklinde gerçekleşmektedir (Achanta, Shaji, Smith, Lucchi, Fua ve Süsstrunk, 2012; Banerjee ve Mery, 2016; Màrquez-Neila, Baumela ve Alvarez, 2014). Çalışmadaki deneyler, Esther Gonzalez-Sànchez tarafından oluşturulan AMIDB (Mathematical Analysis of Images, AMI) isimli iki boyutlu (2D) insan kulak görüntü veri kümesi üzerinde gerçekleştirilmiştir (Gonzalez-Sànchez, 2008).

Literatürdeki çeşitli kulak görüntü veritabanları ve veri kümelerine bakıldığında; Tomczyk ve Szczepaniak (2019) çalışmasında belirtildiği gibi farklı veritabanları veya veri kümeleri için birbirinden farklı nesnel ölçümler ve ölçütler (metric) kullanılabilmektedir. Bazen başarım değerlendirmede tek pozdaki tek açıdan çekilmiş görüntü kullanılırken, sadece sol kulak, sadece sağ kulak veya her ikisi birden kullanılabilmektedir. Bu durum çalışmaların birbirleriyle kıyaslanabilirliğini olumsuz yönde etkileyebilmektedir. Çalışmamızda AMIDB veritabanındaki yedi farklı poz açısından (etiket) ve her iki kulak birden değerlendirmeye alınmış, böylece veritabanı sayesinde daha tutarlı bir deney ortamı oluşturulmuştur.

Kulak tespitini görüntü içerisindeki nesne veya nesnelerin kenar tespitine dayanan kulak konumlandırma (ear localization) doğruluğu veya tespit doğruluğu ile değerlendiren birçok çalışmada cilt renginin ve bölgesinin de dikkate alındığı görülmektedir. Bu tarz kulak tespiti çalışmalarında AWE veri kümesi (Emeršič, Štruc ve Peer, 2017), UND (University of Notre Dame, 2015) ve USTB (University of Science and Technology Beijing, 2002) veritabanları gibi çeşitli veri kümeleri kullanılmıştır (Emeršič, Gabriel, Štruc ve Peer, 2015). Bunlar oluşturulurken; koşullu bir biçimde (sabit noktada duran bireylerin) veya kısıtlı bir ortamda (kapalı iç mekân) görüntüler elde edilebildiği gibi Internet ortamından ve dış mekân dahil değişik ortamlardan (in-the-wild) görüntüler de elde edilebilmektedir. Koşullu ve genellikle kapalı iç mekânda kısıtlar altında oluşturulan veritabanlarındaki biyometrik değerlendirme sonuçları kıyaslama (benchmarking) yapmaya daha uygun bir ölçüm sınaması sağlamaktadır (Wang, Yang ve Zhu, 2021). Çalışmalarda görüntü işleme, makine öğrenmesi veya derin öğrenme yöntemleri ile yapılan deneylerdeki başarım ölçümlerinde bilişim teorisinden (information theory) bilgi elde etme (information retrieval) alanındaki birçok nesnel ölçüt kullanılarak başarım değerlendirme sonuçları elde edilmektedir (ElNaggar, Abaza ve Bourlai, 2018). Genellikle, cilt rengi tespit edilerek kulak bölgesi içeren görüntüden cilt bölgesinin ayrıştırılmasında çeşitli renk uzayları kullanılmaktadır. Bu sayede hem gürültü olarak görüntü bölütlemeyi etkileyecek ışıklandırma koşuluna bağlı piksel parlaklık yoğunluk farklılıklarının önüne geçilmeye hem de kulak dış çevritinin daha baskın olarak görüntüden elde edilmesine dair bir önişlem (preprocessing) gerçekleştirilmektedir (Jacob ve Raju, 2011).

Bu makale aşağıdaki şekilde organize edilmiştir. İkinci bölümünde uygulanan yöntemlerin detaylarına yer verilmektedir. Böylece verilen görüntülere önişlem yapılması ve iteratif kümeleme yöntemiyle süperpiksel tabanlı bölgelerin oluşturulması anlatılmaktadır. Bu bölgeler temel alınarak oluşturulan kulak bölgesine dair aday çevritler içerisinden en uygun olarak en dıştaki çevritin morfolojik jeodezik aktif çevrit yöntemiyle belirlenerek çizge kesmeye dayanan iki seviyeli bölütlemede kullanılmak üzere maske görüntünün oluşturulması incelenmektedir. Bu yolla çalışmadaki tam otomatik bölütlemeye dair detaylara yer verilmektedir. Üçüncü bölümde, deneysel sonuçlar ve tartışmaya yer verilerek AMIDB veri kümesi üzerinden yapılan deneylerden elde edilen görsel nitel ve nesnel nicel sonuçlar sunulurken, bunun yanı sıra yaklaşımımızdaki yöntemlere dair parametrik değerlere de yer verilmektedir. Dördüncü bölüm olan sonuç bölümünde ise yapılan çalışmaya dair elde edilen bilimsel bulgulara ve sonuçlara dayanan tartışmaya yer verilerek, alanla ilgili çeşitli önerilere değinilmektedir. 


\section{YÖNTEM}

Kulak bölgesinin bölütlenmesi konusu, öncelikle renkli görüntülerden özellikle günlük hayattan koşullu veya koşulsuz olarak alınarak oluşturulan bir görüntü veri kümesinin toparlanması, bu veri kümesinin üzerinde çeşitli yöntemlerin denenmesini ve bunlar arasında başarım kıyaslaması yapılabilmesine olanak tanımaktadır. Farklı renk uzaylarında görüntü bölütleme yapılmasında sıklıkla kümeleme (clustering), eşikleme (thresholding), bölge tabanlı (region-based) veya kenar tabanlı (edgebased) bölütleme yaklaşımları kullanılmaktadır. İlgilenilen nesne (Object of Interest, OOI) içeren bölgenin arka plandan ayrılarak ön planda etiketlenmesi en sık uygulanan yaklaşımdır. Bu sayede iki seviyeli bölütleme (bi-level segmentation) işlemi heterojen bölgelerin kenarlarla ayrıştırıldığg, homojen veya benzer özellikteki bölgelerin ise belirli nesneler olarak işaretlendiği bir süreç olarak karşımıza çıkmaktadır (Khattab ve ark., 2014).

Basit doğrusal iteratif kümeleme (SLIC) yöntemi $k$-ortalamalar ( $k$-means) kümeleme yönteminin süperpiksel bölgeleri elde etmeye uyarlanmış biçimi olarak görülebilir. Süperpikselleri oluşturan algoritmalar ya çizge (graph) tabanlı ya da eğimli çıkış (gradient-ascent) tabanlı olabilmektedir. Bu algoritmalar görüntü içerisindeki pikselleri anlamlı atomik bölgelere gruplandırmakta, böylece bölütleme işlemi daha hızlı ve kaliteli hale gelebilmektedir. Çizge tabanlı algoritmalar her bir piksele bir çizgenin bir düğümü olarak davranırken, eğimli çıkış algoritmaları piksellerin ilk kümesi ile başlayıp süperpiksellerin oluşturulduğu nihai biçime karşılık gelen yakınsama kriterine kadar iteratif olarak kümeleri oluşturmaktadır. Süperpiksellerin oluşturulmasında görüntüdeki nesne konumlarının kaybolmamasına dikkat edilmesi önemli bir konudur.

SLIC yöntemi, eşit büyüklükte süperpikseller üreten, $k$ adet kümenin ilk merkez noktalarının belirlenmesinin ardından görüntüdeki pikselleri iteratif olarak arama alanı içerisinde kaldıkları en yakın küme merkezine ilişkilendiren bir algoritmaya sahiptir (Achanta ve ark., 2012). SLIC algoritmasında, ilgili piksel ile ilgili küme merkezi arası mesafe labxy renk görüntü düzlemi uzayında beş boyutlu öklid uzaklığı olarak her adımda hesaplanır. Böylece piksellerin ilgili kümeye dahil olduğu bölge oluşturulur. Güncelleme adımına kadar hata miktarı hesaplanarak piksellerin en yakın küme merkezine olan ilişkisi kurulur. Böylece güncelleme adımında küme merkezinin yeni konumu hata miktarı değeri göz önüne alınarak belirlenir. Bu işlemlerin çizge tabanlı algoritma ve bazı diğer algoritmalara göre hesapsal karmaşıklığı oldukça düşüktür ve $O(N)$ olarak işlenmektedir.

Çevrit gelişim (evolution) yöntemleri özellikle iki seviyeli bölütlemede kullanılmaktadır. Jeodezik aktif çevrit (geodesic active contour, GAC) ve bunun bir çeşiti olan morfolojik GAC, görüntüde ilgilenilen nesne (ön plan) ve arka plan olarak iki bölgeyi ayrıştıran sınır çizgisi etrafına denk gelen bir çevriti bulmayı amaçlamaktadır. Bu yöntemin parlaklık (intensity) ve eğim (gradient) gibi öznitelikler kullanılarak bir gömülme (embedding) fonksiyonunun kısmi diferansiyel denklemlerinin çözümüne dayanan bir çalışma mekanizması vardır. Bu gömülme fonksiyonu sıfır seviyesindeki kümeyi çevrit olarak alır ve çeşitli nesne sınırlarını hesaplayarak her bir adımda çevriti günceller. Bu güncelleme esnasında görüntüdeki parlaklık ve eğim farklı bölgeler için hesaplanmakta fakat sınır bölgesinde genellikle hesaplama durdurulamamaktadır. Burada jeodezik terim sayesinde eğri gelişimi hesaplaması durdurularak uygun sınır bölgeleri oluşturulur (Banerjee ve Mery, 2016; MàrquezNeila ve ark., 2014).

Açma (open) ve kapama (close) gibi çeşitli matematiksel morfolojik işlemler GAC yöntemiyle enerji tabanlı bir biçimde uygulanmakta, minimum enerjili yüzey veya eğri hesabı yoluyla hesaplanan bir jeodezik terim elde edilmektedir. Bilgi içermeyen alanlara çevrit eğrisinin takılıp kalmaması için bir balon kuvveti terimi de morfolojik GAC yönteminde mevcuttur (Cohen, 1991). Màrquez-Neila ve ark. (2014) çalışmasında yılan (snake) olarak ifade edilen bir eğrinin $I$ görüntü içeriğini ifade edecek şekildeki bir enerji fonksiyonu biçeminde tanımlanan çevrit ile oluşturulabildiği ifade edilmektedir. Buna dair Eşitlik (1) aşağıda verilmektedir. Burada $z$ terimi yılan eğrisini, $C$ terimi ise enerji tabanlı hesaplanan çevriti ifade etmektedir.

$$
\begin{aligned}
E(C) & =\int_{0}^{\text {uzuniuk }(C)} g(I)(C(z)) d z \\
& =\int_{0}^{1} g(I)(C(r))\left|C_{r}\right| d r
\end{aligned}
$$

Burada, Eşitlik (1) ‘deki öklid uzaklığı biçimindeki eğri uzunluğu parametresi olarak $d z=\left|C_{r}\right| d r$ parametresi kullanılmıştır. Böylece görüntüdeki kenarların belirlenmesinde Gauss filtresine dayanarak oluşturulan ve Eşitlik (1) eşitliğinde de verilen 
terim $g(I): \mathbb{R}^{d} \rightarrow \mathbb{R}^{+}, x \rightarrow g(I)(x)$ olarak ifade edilmekte ve görüntü içerisinde ilgilenilen bölgenin seçilmesini sağlamaktadır. Aynı çalışmada morfolojik GAC kısmi türevli denklemlerinin morfolojik balon, çekim kuvveti ve morfolojik yumuşatma (smoothing) bileşenleri bu Eşitlik (1) eşitliğine eklenip çözümlenmiştir. Buna göre çalışmamızdaki morfolojik GAC yukarıda bahsedilen diğer temel parametrelerin yanı sıra dört temel parametreye bağlı çalışmaktadır. Durdurma kriterinin (stopping criterion) parametreleri olan alfa ve sigma parametreleri balon kuvveti terimi parametresi (genişleme kuvveti), bunların yanı sıra balonun ve yumuşatmanın eşikleme (thresholding) parametresi çalışmamızda görüntü içerisindeki kulak nesnesi için dış çevritin uygun biçimde gelişim hesaplamasında kullanılmaktadır. Bu parametrelerin teknik detayına Màrquez-Neila ve ark. (2014) çalışmasında yer verilmiştir.

GrabCut yöntemi Gauss karışım modelleri (Gaussian mixture models, GMM) kullanarak renk uzayındaki parlaklıklara istinaden ön plan ve arka plan bölgelerini öğrenmektedir. Çizge kesme yaklaşımında görüntüdeki kenar ve bölgesel bilgilere dayanarak bir enerji fonksiyonu oluşturulur ve iteratif olarak eniyilemesi (optimization) yapılır. Çizge kesme süreci öncelikle bir kullanıcının ilklendirme amacıyla yarı interaktif (etkileşimli) bir yoldan ilgilenilen nesnenin etrafına ilgilenilen nesneyi kapsayan bir dikdörtgen (kapsayan kutu) çizmesi ile başlar, ayrıca nesneye göre dışta kalan ve içte kalan bölgeleri belirler. Buna göre görüntü her bir pikselin etiketlenerek çizgede bir düğüme (node) atandığı ağırlıklandırılmış bir çizge olarak modellenmiş olur. Kaynak (source) ve bitiş (sink) terminalleri olarak iki düğüm oluşturularak çizge tamamlanır.

Literatürde min-cut ismi verilen yöntem sayesinde bu yarı interaktif yaklaşıma dayanan çizge, kaynak ile bitiş terminallerinin ayırdığı iki farklı düğüm kümesine bölünür. Bu işlem kenar (edge) olarak ifade edilecek olan kısmın komşu pikseller arasındaki hesaba dayanan ağırlıkların atanması sayesinde çizge kesme olarak yapılır (Banerjee ve Mery, 2016). Bu yolla bu dikdörtgen içerisinde kalan her bir etiketlenmemiş piksel ön plana veya arka plana ait olarak etiketlenerek yakınsama sağlanana kadar iteratif olarak süreç devam eder. Tushar (2018) çalışmasında Hue-Saturation-Value (HSV) renk uzayında GrabCut yöntemini kullanarak otomatik bölütleme yoluyla cilt lezyonu ön plan görüntüsü elde etmeyi başarmıştır. Önişlemden geçirilen görüntülerde ayrıştırılmak istenen bölge ile uzman tarafından işaretlenmiş referans bölge (ground-truth) benzerlik oranı Jaccard endeksi değeri olarak ölçülmüştür.

Çalışmamızda GrabCut yönteminde otomatik çizge kesme yapılması için gerekli olan arka plan ve ön plan modellerinin oluşturulmasında nesneyi çevreleyen kısıtlayıcı kapsayan kutu (bounding box) şeklindeki ilklendirme (initialize) dikdörtgeninin belirlenmesi yoluyla çizge kesme işlemi veya belirli bir eşik değerine göre kapalı dolgu alanı biçemindeki maske görüntünün (0 ve 1 değerli piksellerden oluşan siyah beyaz görüntü) elde edilmesinde morfolojik GAC yöntemiyle belirlenen insan kulağına dair en dıştaki çevritin kapsadığı bölgeden yararlanılmıştır. Buradaki kapsayan kutu, görüntü işleme alanında genellikle kullanılan dışbükey zarf (convex hull) yöntemi temel alınarak oluşturulmuştur. Buna göre insan kulağına dair en dıştaki çevritin azami uç değerli köşe noktalarına dokunan kenarlara sahip bir dikdörtgen belirlenmiştir. Bu çevriti kapsayacak biçimde kapsayan kutu otomatik olarak görüntüye yerleştirilmektedir. GrabCut yönteminin ilklendirme koşulu için belirli bir eşik değeri dikkate alınarak, bu maskeyle görüntüdeki kapalı dolgu alanının mı yoksa kısıtlayıcı kapsayan dikdörtgenin mi seçilerek işleme başlanacağı belirlenmektedir. Morfolojik GAC yöntemi ise verilen görüntünün SLIC yöntemiyle elde edilen süperpiksel küme bölgeleri olarak elde edilmiş kaba hatlı bölgeler üzerinden çalıştırılarak kulak nesnesini kapsayan uygun en dış çevriti ve buna dair kapalı dolgu alanını oluşturmaktadır. Maske ile ifade edilen nesneye dair bölgenin (kapalı dolgu alanı) dişarısında kalan alanların belirlenmesi ve bu yolla GrabCut yöntemiyle iki seviyeli bölütlemenin tam otomatik olarak yapılması da sağlanmıştır. Bu iki alternatife (kapalı dolgu alanı veya kapsayan kutu kullanımı) uygun ön plan ve arka plan modelleri otomatik olarak oluşturulup kapsama durumlarına göre GrabCut yöntemine gönderilmektedir. GrabCut yönteminin gerekli iterasyon kadar çalıştırılmasıyla eniyilenmiş ön plan maskesi oluşturulmaktadır. Aşağıdaki Şekil 1'de çalışmamızda önerilen yaklaşıma dair akış şeması verilmektedir. 


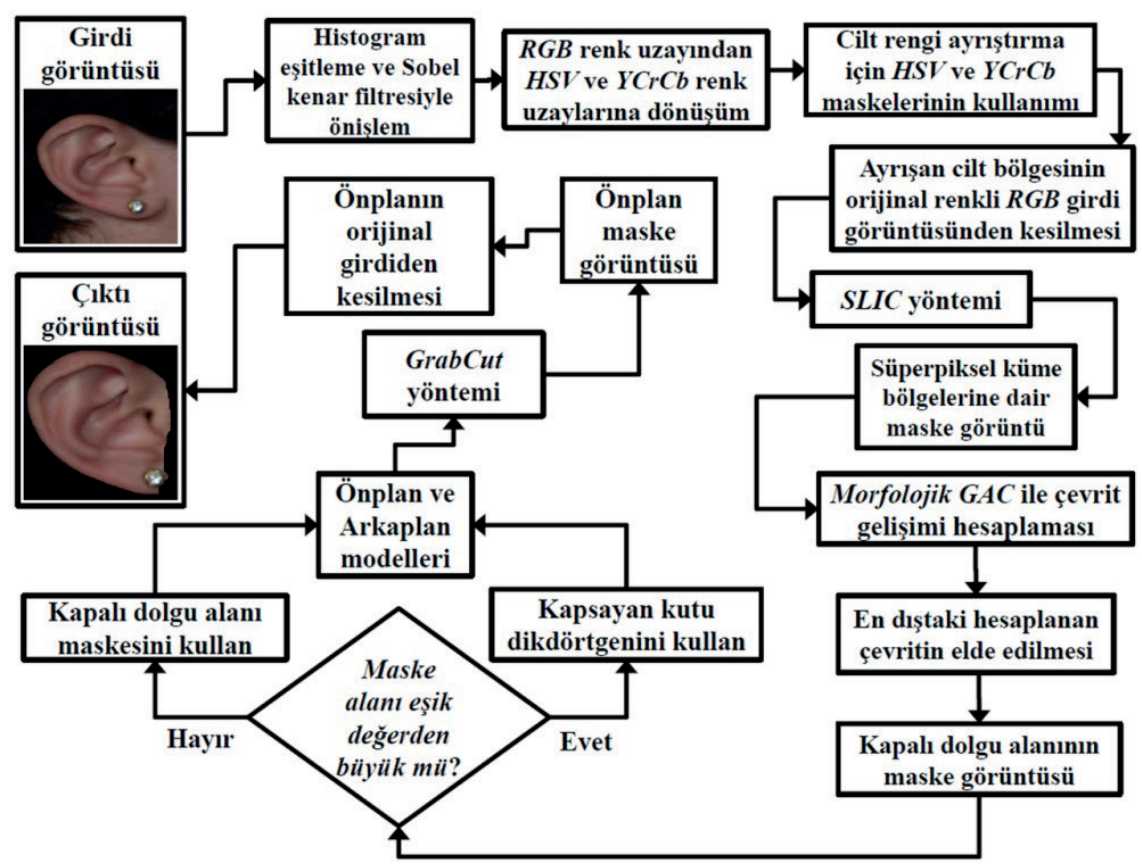

Şekil 1. Önerilen yaklaşımın akış şeması.

Şekil l'de görülebileceği gibi renkli $R G B$ görüntü girdi olarak alınarak gerekli önişlemlerden geçirildikten sonra sırasıyla SLIC yöntemine, oradan morfolojik GAC yöntemine geçirilmektedir. En son olarak GrabCut yöntemine bu iki yöntemin uygulanmasıyla elde edilen ilgili maske görüntüsü geçirilerek nihai aşamada ön plan olarak işaretlemesi yapılmaktadır. Bu sayede kulak bölgesinin arka plandan kesilmesiyle elde edilen nihai maske görüntüsü kullanılarak renkli görüntüden kesilen kulak bölgesini içeren çıktı görüntüsü elde edilmektedir. Yapılan deneylere ve yaklaşımımızda kullanılan yukarıda anılan yöntemlere dair çeşitli parametrik detaylara sonraki bölümde yer verilmektedir.

\section{DENEYSEL SONUÇLAR VE TARTIŞMA}

Çalışmamızdaki deneylerde Esther Gonzalez-Sànchez tarafından oluşturulan iki boyutlu (2D) insan kulağı görüntüleri veri kümesi AMIDB kullanılmıştır. İspanya'daki bir üniversitede yaşları 19 ilâ 65 arası değişen 100 farklı bireyden koşullu bir biçimde (sabit noktada duran bireylerin) altı farklı açıda sağ kulak ve sol kulak görüntüsü sabit ışık ve kamera uzaklığında kaydedilmiştir. Bu veri kümesinde görüntüler her birey için yedi farklı etiket ile sunulmuştur. Bunlar arka (back), ön (front), yukarı (up), aşağı (down), sol (left), sağ (right) ve yakın (zoom) olarak verilmiştir. AMIDB veri kümesinde her biri 492x702 piksel çözünürlükte olan $R G B$ renk uzayında tanıml 700 adet JPEG formatında görüntü yer almaktadır. Bu görüntüler ilgili deneye katılan ilgili bireyin tanımlayıcı numarasıyla ve çekim şartı (arka, ön, yukarı, aşağı, sol, sağ ve yakın) olarak etiketlenmiştir. Veri kümesi dört adet alt kümeye (subset) bölünmüş olarak ilgili Internet adresinde sunulmuştur (GonzalezSànchez, 2008).

Çalışmamızda saç ve diğer kulak harici nesnelerin tespit ve bölütlemeye etki etmemesi adına önişlem aşamasında histogram eşitleme yoluyla 1şıklandırma ve renk ton farklılıklarından kaynaklı bölütleme sorunlarını en aza indirecek bir yol izlenmiştir. Ayrıca, literatürde sıklıkla kullanılan Sobel kenar filtresi de görüntüye uygulanarak kulak çevrit tespitine yardımcı olacak cilt ilâ cilt olmayan bölgeler arasında eğimin oluşması sağlanmıştır. Ardından diğer renk dağılımlarından cilt rengini ayrıştırmak için $\mathrm{HSV}$ ve $\mathrm{YCr} C b$ renk uzaylarında uygun maskeler elde edilerek orijinal $R G B$ renkli resimdeki cilt bölgesi elde edilmiştir. $Y C r C b$ renk uzayında parlaklık $(Y)$, kırmızı renk $(C r)$ ve mavi renk $(C b)$ bileşenleri mevcuttur. Burada $H S V$ renk uzayı kullanılması renk dağılımlarının tepe noktası (mode) tespitinde yararlı olmaktadır. Böylece bu renk uzayı modeli renkli bölgelerin görüntü içerisinde daha belirgin olarak ayrıştırılabilmesine yardımcı olmaktadır. $\mathrm{YCr} C b$ renk uzayındaki yapılan işlem sayesinde parlaklık $(Y)$ bileşenin ayrıştırılmasıyla piksel bazlı parlaklığa bağlı yoğunlukların renk bileşenleri olan kırmızı renk $(\mathrm{Cr})$ ve mavi renk $(\mathrm{Cb})$ bileşenlerinin üzerindeki etkisi azaltılabilmektedir (Jacob ve Raju, 2011). Bu işlem cilt bölgesinin diğer bölgelerden ayrıştırılmasında oldukça iyi sonuçlar alınmasına da yol açmaktadır. Bu işlemin ardından 
bu cilt bölgesinden oluşan ve orijinal renkli $R G B$ görüntüden kesilerek elde edilen renkli görüntü doğrudan SLIC yöntemine geçirilmiştir. SLIC yöntemiyle toplam en fazla yedi küme merkezi olacak şekilde süperpiksel küme bölgeleri cilt bölgesini içeren bu görüntüden elde edilmiştir. SLIC çıktısı morfolojik GAC yöntemine aktarılarak çevrit gelişimi jeodezik terime uygun olarak ilerletilmiş elde edilen kulak nesnesi kapsayan en uygun dış çevritin içerisinde kalan kapalı eğri alanında dolgu yapılmıştır. Bu sayede maske görüntü olarak (siyah beyaz) bir görüntü elde edilmiştir. Buna göre görüntüde arka plan siyah renkli piksellerle ön plan ise beyaz renkli pikseller ile ifade edilmektedir.

Deneylerde SLIC yöntemi için literatürdeki Achanta ve ark. (2012) temel çalışmasında kullanılan parametrelerin belirtilen aralıkları göz önüne alınmıştır. Ayrıca, Walt ve ark. (2014) çalışmasında belirtildiği haliyle Scikit-Image görüntü işleme kütüphanesinin Python programlama dili paketinin görüntü bölütleme modülündeki SLIC yöntemiyle ilgili parametreleri dikkate alınmıştır. Çalışmamızda oluşturulan sinerjik yaklaşıma bu parametrelerin uygunluğu göz önünde bulundurularak deney parametrelerinin el ile belirlenen ilklendirilmiş (initialize) değerleri olacak şekilde; Gauss yumuşatması çekirdek büyüklüğü olarak sigma parametresi 4, renk yaklaşıklığı ve uzamsal yaklaşıklık için yoğunluk (compactness) parametresi 4 ve azami küme sayısı 7 olarak belirlenmiştir. Buna göre SLIC ve sıradüzensel çizge birleştirme yapılması sayesinde süperpiksel bölgeleri oluşmaktadır. Bu küme bölgelerinden oluşan görüntü gri tonlamalı hale getirilerek morfolojik GAC yöntemine verilmektedir. Bu morfolojik GAC yöntemi için alfa parametre değeri 2300, sigma parametre değeri 5,58 alınmış, balon kuvveti terimi 1 alınarak, eşikleme değeri ise 0,41 olarak belirlenmiştir. Buradan elde edilen diş çevrite dair (kulağ 1 kapsayan en dış çevrit) iç bölge kapalı dolgu alanı haline getirilmekte böylece siyah beyaz renkte maske görüntüsü oluşturulmaktadır. Morfolojik GAC ile oluşturulan maskenin kullanılmasıyla eğer belirli bir eşik değerinin altında kalıyorsa ön plan ve arka plan modelleri otomatik bir biçimde oluşturularak GrabCut yöntemi çalıştırılmaktadır. Bu eşik değeri dolgunun kapladığı alan büyüklüğünün görüntünün \%50’lik kısmına denk gelip gelmediğini kontrol eder. Eğer belirlenen eşik değerinden bu dolgu alanı büyükse doğrudan ilklendirme dikdörtgeni kullanılarak otomatik bir biçimde ön plan ve arka plan modelleri oluşturulup GrabCut yöntemi çalıştırılmaktadır. Bu işlemde kulak nesnesinin içerisinde bulunduğu içte kalan bölge (ön plan modeli) için morfolojik GAC yönteminin yukarıda verilen parametrik değerlerle 355 iterasyon sonucunda ürettiği bölge kullanılmaktadır. GrabCut yöntemi iterasyon sayısı ise 5 olarak belirlenmiştir.

Orijinal girdi görüntüsü ve bu maske görüntüsü kullanarak GrabCut çizge kesme yöntemi çalıştırılmaktadır. GrabCut tarafından yapılan kesme işlemi sonucunda oluşturulan yeni maske görüntüsü sayesinde ön plan olarak işaretlenen kulak bölgesi arka plandan kesilerek renkli çıktı görüntüsü olarak elde edilmektedir. Aşağıdaki Şekil 2'de AMIDB veri kümesinden rasgele seçilen dört farklı görüntü için sırasıyla Şekil 2 (a) orijinal renkli görüntü, Şekil 2 (b) SLIC süperpiksel küme bölgeleri, Şekil 2 (c) morfolojik GAC en dış çevritiyle oluşturulan kapalı dolgu alanına uygun maske görüntü, Şekil 2 (d) GrabCut için nesneyi kapsayan kutu olarak ilk dikdörtgen bölge, Şekil 2 (e) GrabCut ile çizge kesme sonucu elde edilen yeni maske görüntüsü, Şekil 2 (f) renkli çıktı görüntüsü olarak verilmektedir. Şekil 2'deki satır numaraları ile belirtilen sırasıyla 1) “002_up_ear", 2) “020_front_ear", 3) “056_zoom_ear" ve 4) “090_zoom_ear" isimli görüntüler ve bunların yukarıda anılan yöntemlerle işlenmiş halleri verilmektedir. 

(a)
(b)
(c)
(d)
(e)
(f)
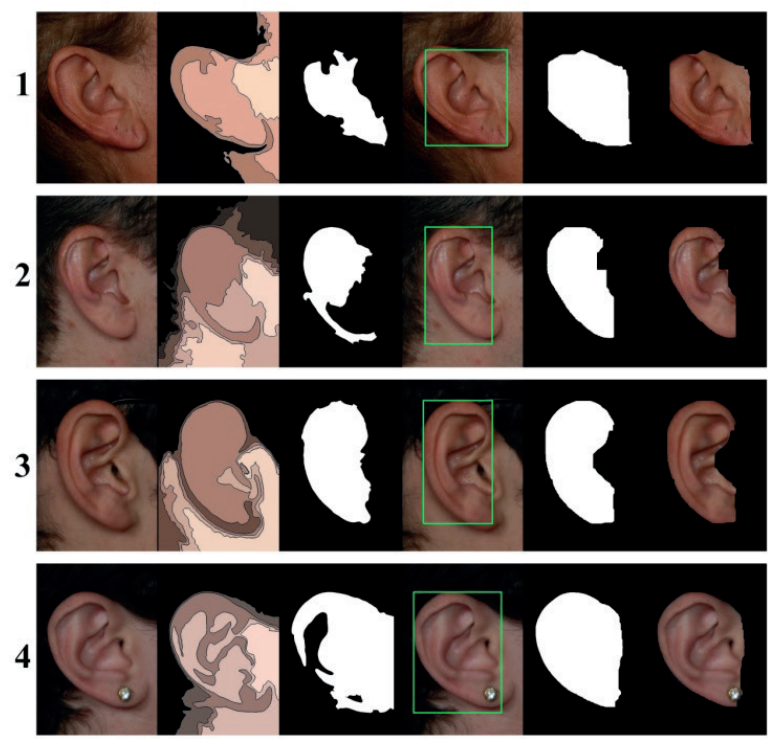

Şekil 2. AMIDB deneysel sonuçlar.

Deneylerde uzman tarafından işaretlenmiş referans (ground-truth) bölge maske görüntüsü ile programatik olarak tespit ve bölütlemesi yapılmış bölgenin karşıllaştırılmasında; birleşim kesişimi (Intersection over Union, $I o U$ ) olarak tarif edebileceğimiz Jaccard endeks değerleri kullanılmıştır. Bir sınıflandırmada doğru olarak sınıflandırılan veya yanlış olarak sınıflandırılan pikselleri ifade etmek için bilişim teorisinden bilgi elde etme (information retrieval) alanındaki doğru pozitif (true positive, $T P$ ), yanlış pozitif (false positive, $F P$ ), doğru negatif (true negative, $T N$ ) ve yanlış negatif (false negative, $F N$ ) ölçümleri kullanılmaktadır. Buna göre; TP değeri tespit edilmesi istenilen bölge piksellerinin kaç tanesinin doğru olarak programatik biçimde bu bölgede tespit edilmiş olduğunu gösterilmektedir. $F N$ değeri tespit edilmesi istenilen bölge piksellerinin kaç tanesinin yanlış olarak programatik biçimde bu bölgenin dışarısında tespit edilmiş olduğunu gösterilmektedir. FP değeri ise tespit edilmesi istenilen bölgenin dışında kalan piksellerin kaç tanesinin yanlış olarak programatik biçimde bu tespit edilmek istenilen bölgenin içerisinde tespit edilmiş olduğunu göstermektedir. Bu ölçümleri içeren Jaccard benzerlik endeksi (katsayısı) ölçütü aşağıdaki Eşitlik (2) ile ifade edilmektedir (Tushar, 2018). Bu ölçüt ile [0,1] aralığında değerler elde edilmekle birlikte literatürdeki bazı çalışmalarda ise bu değerler yüzdelik orana dönüştürülerek de verilebilmektedir.

$$
\text { Jaccard }=\frac{|T P|}{(|T P|+|F P|+|F N|)}
$$

Elde edilen deneysel sonuçlarda büyük oranda kulak bölgesinin doğru konumunda ve tam olarak bölütlendiği görülmektedir. Şekil 3'deki satır numaraları ile belirtilen sırasıyla 1) "002_up_ear", 2) "020_front_ear", 3) "056_zoom_ear" ve 4) "090_ zoom_ear" isimli görüntüler deneylerde kullanılan görüntüler arasından rasgele seçilmiştir. Bu dört görüntüye ait Jaccard benzerlik endeksi değerleri, aşağıdaki Şekil 3’te verilmektedir. 
(a)

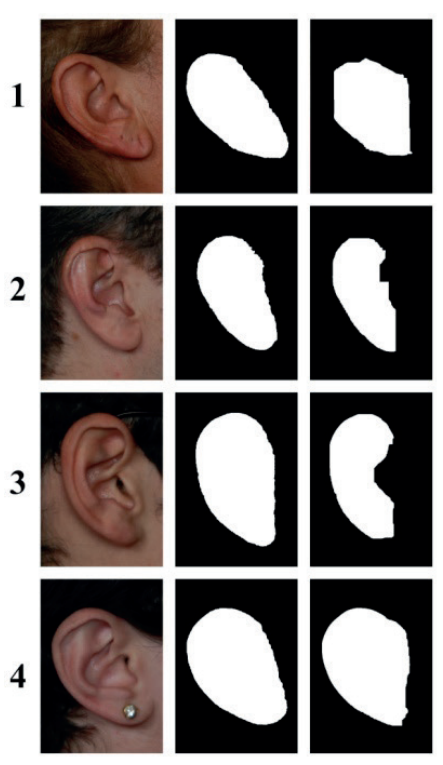

(d)

Benzerlik ölçümü

Jaccard endeks değeri: $\mathbf{0 , 8 6 8 1}$

Jaccard endeks değeri: $\mathbf{0 , 8 9 7 8}$

Jaccard endeks değeri: $\mathbf{0 , 8 4 0 8}$

Jaccard endeks değeri: 0,9250

Sekil 3. Jaccard benzerlik endeks değerleri.

Şekil 3’te (a) orijinal görüntü, Şekil 3 (b) referans (ground-truth) görüntü, Şekil 3 (c) çalışmamızda önerilen yaklaşımın ürettiği çıktı maske görüntüsü ve Şekil 3 (d) ilgili görüntü için Jaccard endeks değeri verilmektedir. Referans (ground-truth) olarak uzman tarafından el ile işaretlenen arka planı (siyah) ve ön planı (beyaz) ifade eden görüntü kullanılmıştır. Bu referansla yapılan kıyaslamada nesneye karşılık gelen programatik olarak çalışmamızda üretilmiş çıktı maske görüntüsünün benzerlik oranı (örtüşümün birleşime oranı) veya birleşim kesişimi (Intersection over Union, $I o U$ ) olarak tarif edebileceğimiz Jaccard endeks değerlerine bakıldığında (bu değerler yüzdelik orana dönüştürüldüğünde) \%84 ilâ \%92 arasında bir birleşim kesişimi (benzerlik oranı) ile deneylerde referans veri ile karşılaştırıldığında oldukça iyi sonuçlar elde edildiği görülmektedir. AMIDB veri kümesinde sirasiyla subset-1, subset-2, subset-3 ve subset-4 isimli dört ayr1 alt küme bulunmaktadır. Tüm bu alt kümelerdeki toplamda 700 adet görüntü üzerinden ortalama Jaccard endeks değeri $(I o U)$ hesaplandığında standart sapma miktarı da göz önüne alınarak \%86,32 $\pm 0,6$ olduğu görülmektedir.

Literatürde AMIDB veritabanından farklı veritabanları için bu ölçütle veya farklı ölçütlerle deneysel sonuçlar elde eden çalışmalar da mevcuttur (Wang, Yang ve Zhu, 2021). Emeršič ve ark. (2015) çalışmasında belirli bir koşula bağlı olmayan ortamdan alınarak etiketlenmiş ağ kulak görüntüleriyle oluşturulan AWE veri kümesi (Emeršič, Štruc ve Peer, 2017) üzerinde piksel çapında kulak tespitine dayanan kodlayıcı kod çözücü (encoder-decoder) sinir ağı ile yapılan deneylerle bazı Jaccard endeksi $(I o U)$ değerleri elde edilmiştir. Emeršič ve ark. (2015) çalı̧̧masında AWE veri kümesi için ortalama Jaccard endeks

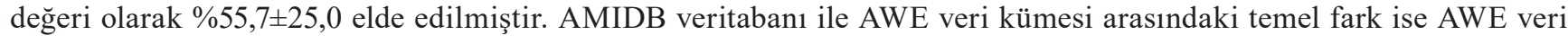
kümesinin AMIDB veritabanının aksine koşula veya kısıta bağlı olmaksızın (in-the-wild) oluşturulmuş olmasıdır. Böyle görüntülerde insanın kafa bölgesinin yan profilden görünmesi veya yüz bölgesinin tamamen görünür olup olmaması kulak bölgesinin tespitini, bölütlenmesini veya tanınmasını daha farklı bir konu başlığı altında incelenebilecek hale getirmektedir (Wang, Yang ve Zhu, 2021).

Birçok çalışmada kulak bölütleme; kulak tespiti veya kulak tanımanın bir ilk adımı olarak görülmekte, basit eşikleme ile bölütleme veya elle işaretlenen bölgeler üzerinde aktif çevritin işletilmesiyle kulak konumlandırma (localization) yapılmaktadır. $\mathrm{Bu}$ çalışmalarda yoğunlukla, tespit doğruluk oranı, yanlış tespit oranı veya benzeri nesnel ölçütler üzerinden bir başarım değerlendirme yapılmaya çalışılmaktadır. Doğruluk oranı (accuracy) ölçütü Jaccard endeksi yanı sıra çalışmalarda başarım değerlendirme için kullanılmaktadır. Aşağıdaki Eşitlik (3) ile doğruluk oranı ifade edilmektedir (Emeršič, Gabriel, Štruc ve Peer, 2015). Bu ölçüt ile $[0,1]$ aralığında değerler elde edilmekle birlikte literatürdeki bazı çalışmalarda ise bu değerler yüzdelik orana dönüştürülerek de verilebilmektedir. 


$$
\text { Doğruluk }=\frac{|T P|+|T N|}{(|T P|+|T N|+|F P|+|F N|)}
$$

Yakından bakıldığında Eşitlik (2) ile Eşitlik (3) arasındaki temel farkın doğru negatif (TN) terimi olduğu görülmektedir. TN değeri tespit edilmesi istenilen bölgenin dışında kalan piksellerin kaç tanesinin doğru olarak programatik biçimde bu bölgenin dışarısında tespit edilmiş olduğunu göstermektedir. Buna göre, doğruluk oranı ile Jaccard endeksi arasında temel farklılık ilgili bölgeler için bakılan örtüşüm oranlarını ne açıdan değerlendirdikleridir. Doğruluk oranı tüm görüntüde kaç tane pikselin doğru olarak sınıflandırıldığını göstermektedir. Çalışmamızda başarım değerlendirme yapılırken, görüntüdeki piksellerin kulak bölgesine ait olarak ne derecede doğru sınıflandırılmış olduğunun oransal olarak ölçülmesi hedeflenmiştir. Buna göre çalışmamızdaki sinerjik yaklaşımla elde edilen kulak bölgesi ve kulak bölgesi dışında kalan bölgelerdeki (saç, cilt vb.) pikseller değerlendirmede dikkate alınmıştır. Doğruluk oranı görüntü içerisinde dengesiz olarak dağılan piksellerden oluşan bölgeler için daha uygun bir ölçüttür. Kulak bölgesi dışında kalan bölgeler (çoğunluk bölgesi) daha fazla pikselin bulunduğu alanları, kulak bölgesi (azınlık bölgesi) ise daha az pikselin bulunduğu alanı ifade ettiği durumlarda doğruluk oranı daha kullanışlı olmaktadır. Literatürdeki çoğu veritabanının aksine AMIDB veritabanı koşullu, kısıtlar altında oluşturulmuş ve bahsi geçen bu iki bölgenin veritabanındaki görüntüden görüntüye farklılık gösterdiği bir yapıdadır. Bazı görüntülerde kulak bölgesi pikselleri çoğunluk sınıfındayken bazılarında ise azınlık sınıfında olabilmektedir. Bu açıdan Jaccard endeksi (IoU), çoğunluk ve azınlık sınıfları arasında piksellerin dağılımından daha az etkilenmesi nedeniyle daha doğru bir ölçüm yapmamızı sağlamaktadır (Emeršič, Gabriel, Štruc ve Peer, 2015). Çalışmamızda nihai çizge kesme adımıyla bölge tabanlı bölütleme (region-based segmentation) yapıldığı ve çoğunluk ile azınlık sınıflarına ait piksellerin AMIDB veritabanında çeşitli alt kümelerde (subset-1, subset-2, subset-3 ve subset-4) farklı bölgesel oranlara sahip görüntülerde farklı sınıflara düşmesi nedeniyle özellikle doğruluk oranı yerine Jaccard endeksi $(I o U)$ tercih edilmiştir. Bu açıdan çalışmamız AMIDB özelinde Jaccard endeksini kullanması nedeniyle literatürdeki diğer çalışmalardan farklı bir özgün bakış açısına sahiptir.

\section{SONUÇ}

Yapılan deneylerde elde edilen görsel nitel (qualitative) sonuçlarda da aynı zamanda nesnel nicel (quantitative) nesnel benzerlik oranı ölçütü (Jaccard endeksi) değerlerinde de oransal olarak kulak bölgesinin konumunun doğru olarak bulunması ve programatik yoldan oluşan nesne sınırları tarafından tam olarak kapsanır oluşu, kullanılan yöntemlerin parametrik değerlerine göre etkin sonuçlar üretmesi ve biyometrik alanında otomatik kulak bölütlemenin popüler bir araştırma konusu olması nedeniyle çalışmamız kendi kapsamında e-sağlık ve turizm alanlarında bireylere uygulanacak biyometrik yetkilendirme ve tanıma ile alakalı diğer çalışmalara temel oluşturabilecek bir yapıdadır.

Çalışmamızdaki deneylerden anlaşılacağı üzere uygun olmayan önişleme algoritmasının oluşturulan sinerjiyi olumsuz etkileyebileceği, böyle bir sinerjinin en çok ilk adımlarda yapılan kümelemeye bağımlı olarak başarımının değişkenlik gösterebileceği anlaşılmaktadır. Önerilen sinerjik yaklaşımdaki aktif çevritin görüntüdeki gürültü olarak tarif edebileceğimiz çeşitli piksellerden ve azınlık sınıfına girmesi gerekirken çoğunluk sınıfına giren veya tam tersi durumdaki piksellerden etkilendiği görülmektedir. Bu açıdan oluşturulan süperpiksel kümelerinin olabildiğince homojen bölgeleri ifade etmesine dikkat edilmelidir. Buna göre SLIC ile elde edilebilecek kümelerde bölge içi homojenlik oluşması adına renk yaklaşıklığı ve uzamsal yaklaşıklık için yoğunluk parametresi etki ettirilerek aktif çevritin işletilmesi sağlanmıştır. Bu esnada oluşan maskenin gürültü oluşturacak piksellerden daha az etkilenmesi mümkün olmuştur. Böylece daha uygun bir çevritin elde edilmesiyle bölge tabanlı görüntü bölütlemede daha uygun bir maske elde edilmesi için GrabCut kullanan çizge kesmeye verilecek kapalı dolgu alanının oldukça iyi biçimde belirlenmesi mümkün olmaktadır. Bu olgular çerçevesinde yapılan çalışmamızda deneysel sonuçlar başarımı açıkça ortaya koymaktadır.

$\mathrm{Bu}$ çalışma özelinde elde edilen sonuçlara dayanarak, ileriki çalışmalarda daha fazla çeşitte kulak görüntü veri kümelerinin üzerinde deneylerin yapılması, farklı kümeleme ve aktif çevrit yöntemlerinin denenerek ön plan ve arka plan ayrımında daha yüksek oranda kapsama ve kulak harici bölgelerin kulaktan daha yüksek doğrulukta ayrıştırılması sonuçlarının elde edilmesi planlanmaktadır. 
Hakem Değerlendirmesi: Dış bağımsız.

Çıkar Çatışması: Yazar çıkar çatışması bildirmemiştir.

Finansal Destek: Yazar bu çalışma için finansal destek almadığını beyan etmiştir.

Peer-review: Externally peer-reviewed.

Conflict of Interest: The author has no conflict of interest to declare.

Grant Support: The author declared that this study has received no financial support.

\section{Kaynaklar/References}

Achanta, R., Shaji, A., Smith, K., Lucchi, A., Fua, P. \& Süsstrunk, S. (2012). SLIC Superpixels Compared to State-of-the-Art Superpixel methods. IEEE Transactions on Pattern Analysis and Machine Intelligence, 34(11), 2274-2282. http://dx.doi.org/10.1109/TPAMI.2012.120.

Banerjee, S. \& Mery, D. (2016). Iris Segmentation Using Geodesic Active Contours and GrabCut. Revised Selected Papers of Image and Video Technology, PSIVT 2015 Workshops, LNCS 9555, (pp. 48-60). Auckland, New Zealand, (Eds., Huang, F., \& Sugimoto, A.), Springer International Publishing Switzerland. http://dx.doi.org/10.1007/978-3-319-30285-0_5.

Chen, H., \& Bhanu, B. (2005, January). Contour matching for 3D ear recognition. Proceedings of the Seventh IEEE Workshop on Applications of Computer Vision Motion and Video Computing (WACV/MOTION2005) (pp. 123-128). Breckenridge, CO, USA. http://dx.doi.org/10.1109/ ACVMOT.2005.38.

Cintas, C., Delriux, C., Navarro, P., Quinto-Sànchez, M., Pazos, B. \& Gonzalez-Josè, R. (2019). Automatic Ear Detection and Segmentation over Partially Occluded Profile Face Images. Journal of Computer Science Technology, 19(1), 81-89. http://dx.doi.org/10.24215/16666038.19.e08.

Cohen, L. D. (1991). On Active Contour Models and Baloons. Computer Vision, Graphics, and Image Processing: Image Understanding, 53(2), 211-218. http://dx.doi.org/10.2016/1049-9660(91)90028-N.

El-Naggar, S., Abaza, A., \& Bourlai, T. (2018, August). Ear detection in the wild using Faster R-CNN Deep Learning. Proceedings of the IEEE/ACM International Conference on Advances in Social Networks Analysis and Mining (ASONAM2018) (pp. 1124-1130). Barcelona, Spain. http://dx.doi. org/10.1109/ASONAM.2018.8508487.

Emeršič, Ž., Gabriel, L. L., Štruc, V., \& Peer, P. (2015). Convolutional Encoder-Decoder Networks for Pixel-wise Ear Detection and Segmentation. IET Biometrics, Special İssue: Unconstrained Ear Recognition, 7(3), 175-184. http://dx.doi.org/10.1049/iet-bmt.2017.0240.

Emeršič, Ž., Štruc, V., \& Peer, P. (2017). Ear Recognition: More than a Survey. Neurocomputing, 255, 26-39. http://dx.doi.org/10.1016/j.neucom.2016.08.139.

Gonzalez-Sànchez, E. (2008). Biometria de la Oreja. (Doctoral Dissertation, Universidad de Las Palmas de Gran Canaria, Spain). Mathematical Analysis of Images Database (AMIDB). http://ctim.ulpgc.es/reseach_works/ami_ear_database.

Jacob, L., \& Raju, G. (2011). Automatic Ear Localization Using An Effective Skin Segmentation Algorithm And Correlation Coefficient in 2D Images. International Journal of Machine Intelligence (IJMI). 3(4), 327-332.

Joshi, K. V., \& Chauhan, N. C. (2011). Edge Detection and Template Matching Approaches for Human Ear Detection. International Journal of Computer Applications, Special Issue for International Conference on Intelligent Systems and Data Processing (ICISD2011), 1(1), 50-55.

Khattab, D., Ebied, H. M., Husein, A. S., \& Tolba, M. F. (2014). Color Image Segmentation Based on Different Color Space Models Using Automatic GrabCut. The Scientific World Journal, 2014, 126025,1-10. http://dx.doi.org/10.1155/2014/126025.

Màrquez-Neila, P., Baumela, L., \& Alvarez, L. (2014). A Morphological Approach to Curvature-based Evolution of Curves and Surfaces. IEEE Transactions on Pattern Analysis and Machine Intelligence, 36(1), 2-17. http://dx.doi.org/TPAMI.2013.106.

Pflug, A., \& Busch, C. (2012). Ear Biometrics: A Survey of detection, feature extraction and recognition methods. IET Biometrics, 1(2), 114-129. http:// dx.doi.org/10.1049/iet-bmt.2011.0003.

Schuckers, M. E., (2010). Computational Methods in Biometric Authentication, Statistical Methods for Performance Evaluation. Information Science and Statistics. Springer-Verlag London Limited.

Tomczyk, A., \& Szczepaniak, P. S. (2019). Ear Detection using Convolutional Neural Network on Graphs with Filter Rotation. Sensors (MDPI), 19, 5510, 1-21. http://dx.doi.org/10.3390/s19245510.

Tushar, F. I., (2018). Automatic Skin Lesion Segmentation Using GrabCut in HSV Colour Space. Computer Vision and Pattern Recognition (cs.cv), ArXiv. 1-3. Retrieved from: https://arxiv.org/abs/1810.00871.

University of Notre Dame. UND Face Database. (2015). Erişim adresi: http://www.nd.edu/cvrl/CVRL/DataSets.html. (Erişim zamanı: 12.03.2021).

University of Science and Technology Beijing. Ear Recognition Laboratory USTB Database. (2002). Erişim adresi: http://wwwl.ustb.edu.cn/resb/en/ doc/Imagedb_123_intro_en.pdf. (Erişim zamanı: 12.03.2021).

Walt, S. V. D., Schönberger, J. L., Nunez-Iglesias, J., Boulogne, F., Warner, J. D., Yager, N., Gouillart, E., \& Yu., T. (2014). Sckit-Image: Image Processing in Python. Peer J. Life \& Enivronment. 2(e453), 1-18. http://dx.doi.org/10.7717/peerj.453

Wang, Z., Yang, J., \& Zhu, Y. (2021). Review of Ear Biometrics. Archives of Computational Methods in Engineering. 28, 149-180. http://dx.doi.org/10.1007/ s11831-019-09376-2. 
